the true diphtheria bacillus and the bacillus of Hoffman from the same culture tube. The bacillus which resembles the true diphtheria bacillus in form and in its power of forming acid out of sugar, and indeed in every other point except that it is devoid of virulence, is not to be distinguished from it in its growth on this mediam. The medium is relatively favourable to the bacillus diphtheriæ and with its aid it is exceedingly easy to obtain pure cultures. On the other hand it has sometimes been found to be unfavourable even for this organism. Under these circumstances it improves when kept for a few weeks. By other means also it has been found that this difficulty can be to some extent overcome - viz., by raising the temperature of sterilisation. ${ }^{2}$ The addition of peptone to the medium has been tried and found to offer no advantage. The beneficial action of the high temperature, therefore, cannot be attributed to partial peptonisation of the medium. It seems more reasonable to attribute it to the dissociation of ammonium sulphide which is undoubtedly formed. Sterilisation in the steam steriliser has been tried, but has been found to yield an unsatisfactory medium. When sterilised at a temperature of $120^{\circ} \mathrm{C}$. the medium is undoubtedly a valuable one, but the bacillus diphtherix even then grows upon it with provoking slowness. Old laboratory coltures accustomed to other soils grow more slowly than do bacilli fresh from the human throat, but even these in most cases do not grow sufficiently rapidly to allow of a probable diagnosis being made within twenty-four hours. On this account I have sought to obtain a similar but more favourable medium from horse serum and have been so far successful that with it I have been sometimes able to sow the medium in the morning and return a diagnosis of diphtheria on the same day.

Preparation of alralised Horse Serum.

Horse serum is treated in the following way. To every 100 c.c. 2 grammes of glucose and from 1.25 to 1.2 c.c. of a 10 per cent. solution of $\mathrm{NaOH}$ are added ; the medium is then poured into tubes and Petri's dishes and sterilised at a temperature of $90^{\circ} \mathrm{C}$. on two successive days in a chamber surrounded with a jacket containing boiling water. Exposure to steam at atmospheric pressure results in the formation of bubbles and the destruction of the medium. Sterilisation in the anfoclave has not been successful. The medium prepared from horse seram is as bright and transparent and almost as light in colour as gelatin. It offers a very favourable soil to the diphtheria bacillus. Staphylococci and streptococoi grow upon it, but the common saprophytes seem to grow with difficulty and no difficulty has hitherto occurred from the presence of liquefying organisms. The diphtheria bacillus grows so rapidly that colonies may often be seen after from six to eight hours' incubation. And it is exceedingly easy to obtain pure cultures with its aid. In some respects it is inferior to the alkalised ox serum, for the colonies of the diphtheria bacillus are not so characteristic as on that medium. They show no tendency to become daisy-shaped and they are neither so grey nor so Iat. The formation of acid, however, causes the medium to become opalescent and in pure cultures this distinguishes the bacillus of Hoffmann, while for the purpose of distinguishing between these two organisms the ox serum is to be preferred. Yet for the ordinary purposes of diagnosis the alkalised horse serum is far better because the growth of the bacillus diphtheria is so much more rapid upon it.

Method OF EMPLOYiNg the Medium For Diphtheria DIAGNOSIS

A swab rubbed over the suspected throat is rubbed over the surface of the serum contained in a Petri's dish. If it has been sent from a distance and has become dry it is previously moistened with broth. The dish is then incubated at $37^{\circ} \mathrm{C}$. and examined on the following day. If the bacillas diphtheria is present colonies of the size of a small pin's head (or smaller if numerous) will be apparent. A coverslip impression specimen is made from these, stained and mounted in Löffler's methylene blue. The advantage of the impression method is obvions, for it allows a large number

2 When the autoclare is heated and the air which it contains is not allowed to escape the internal pressure is due to that exerted by the air together with that exerted by the saturated steam. Under these circumstances the temperature scale usually engraved on the pressure guage of this instrument is misleading, the temperature being in fact many degrees lower than that indicated. It is necessary, therefore, to use a thermometer. Before this was done the serum was often insufficiently heated. The best results have been obtained by exposing the medium to a temperature of $120^{\circ} \mathrm{C}$. for twenty minutes. of colonies to be successively examined in little more than the time usually spent over one, thus increasing the certainty of a negative diagnosis. The impression method was, I believe, first applied to this purpose by Dr. Klein, of St. Bartholomew's Hospital. The alkalised horse serum has worked so well in the Wellcome Physiological Laboratory, London, where it was first made and is now in daily use for the bacterial diagnosis of diphtheria, that I venture to hope that other workers in the same field will make trial of it. Cambridge.

\section{INFLUENZA AND IMMUNITY.}

\section{BY H. G. TURNEY, M.A., M.D. OXON., M.R.C.P. LOND.,} AISISTANT PHYSICIAN TO ST. THOMAg'S HOSPITAL.

INFLUENZA is now so hackneyed a topic for medical writers that mere mention of it has become almost a punishable offence. The only excuses for the present paper are that the point with which it proposes to deal though it possesses both importance and interest has received comparatively little notice and still awaits a final answer, while a considerable recrudescence of the disease has made all things connected with it of importance to the medical practitioner. The question of one attack of the disease protecting from or predisposing to other attacks is one which has been settled in the bodies of many of us, but such an experience remains to a great extent individual and at all events has not been generally expressed in numerical terms. The observations which are here recorded, based principally upon facts obtained in the epidemic of 1891, have hitherto been kept back in the hope that the question of immunity would have been conclasively decided by the statistical method applied on a large scale. The clinical material at the disposal of so many country practitioners, with constituencies remain ing from one epidemic to another practically the same, undoubtedly forms a far firmer basis for such a research than the shifting population of a hospital out-patient room, and if such material were made the subject of collective investigation the result would be finally decisive. The public health authorities, too, possess extensive facilities for prosecuting such an inquiry, though on somewhat different lines and as regards local rather than personal immunity. Of these facilities Dr. Parsons has availed himself to the fullest extent in his classical monographs on influenza. Still these opportunities have their limits, for no public records can follow out the life history of each individual with regard to disease. This can be done only by the medical practitioner and upon him lies the burden of proof.

So far as can be ascertained by limited personal inquiries, the views of medical men on this topic of influenzal immunity are widely divergent; while some maintain that one attack is a fairly efficient protection, others as strongly assert that so far from protecting it renders the subject still more susceptible. It seems incredible that after a series of five wide-spread epidemics occurring within the space of four years a problem of such personal interest to many should still remain unsolved.

The question of immunity may conveniently be considered (1) as regards time and place and (2) as it affects individuals. Space will not permit discussion of the first of these questions and, moreover, little need be said except by way of reference to Dr. Parsons' ${ }^{\prime}$ work on the subject. His conclusions, with a summary of the evidence on which they are based, may, however, be mentioned here in his own words:"In many counties an inverse proportion is perceptible between the death-rates from influenza in 1891-1892, those counties which suffered severely in the former year baving escaped lightly in the latter year and vice versấ." "But," he continues, "certain counties, however, seem prone to a higher death-rate than their neighbours in each year. A severe epidemic of influenza appears to confer upon a locality a certain degree of protection against another."2 Before entering into the question of immunity as it affects individuals it may be well to define the conditions under which that term will be used. Probably in many microbic diseases immunity is a necessary condition of the recovery of the

1 Dr. H. Franklin Parsons: On the Distribution of the Mortality Irom Influenza in Eny 26th, 1894. Also Local Government Board Additional Report on Influenza, p. 53 et seq.

Loc. cit. 
patient, but the completeness and duration of that immunity may vary within the widest limits in different affections. At one end of the scale stand such maladies as scarlet fever and small-pox where the protection conferred lasts in the enormous majority of cases for a lifetime. Of the other extreme diphtheria is perhaps the best example. That diphtheria does confer immunity may, in the light of recent reseach, be taken as proved. But most clinical observers will agree that this protection lasts a comparatively short time-a month or six weeks at the most. This view is confirmed by Behring ${ }^{3}$ as regards his antitoxin. $\mathrm{He}$ estimates the duration of this artificial immunity at from six to ten weeks according to the dose injected, after which time it gradually disappears. It is interesting to note that during this period of resistance the antitoxin is being excreted by the urine. Abel, again, in experimenting with the blood serum of convalescent diphtheria patients finds that guinea.pigs are protected for about a month. It is quite possible, therefore, that a patient may be protected for a period only long enough to allow his recovery from the disease, and in such a case immunity will be clinically non-existent. It is to the presence or absence of clinical immunity that attention will be directed in the following remarks. The degree of immunity may be estimated (1) by experiment, (2) by the tendency to relapse, and (3) by the liability to subsequent attacks.

1. By experiment. - Pfeiffer $^{\frac{5}{3}}$ appears to be the only observer who has published any definite results which may throw light on this point. He expresses his conclusions as follows : "When I repeated the same injection (pare cultures of influenza bacilli) fourteen days later the three monkeys showed much slighter reaction. There appeared to be indications of a form of immunity such as must be supposed to exist in men who have had influenza once." Klein, however, in repeating Pfeiffer's inoculations was unable to satisfactorily confirm his results, the large majority of the experiments proving negative. The question from this point of view must still therefore be regarded as unsettled.

2 and 3 . By relapses and subsequent attacks. - Strictly speaking both relapses and subsequent attacks are alike evidence of the liability of the organism to fresh invasion by the disease, the relapse being so far the more convincing of the two on account of the shorter interval between the first and second injections. On other grounds, however, of these two forms of evidence that based on the tendency to relapse is by far the less satisfactory. Influenza owes much of its importance to its peculiar richness in complications and between a complication and a relapse the line is often indeed difficult to draw. This source of error can hardly be eliminated even by the best observers and must go far to vitiate any statistics bearing on that particular question. And even if this possible fallacy be ignored the common occurrence of relapses in typhoid fever-surely one of the most self-protective of diseases-will raise fresh doubts as to the validity of the argument.

Considering the difficulty of defining a relapse in influenza it is hardly surprising that estimates of its frequency should vary within the widest limits. Symes Thompson? believes that " relapses have occurred in many of the cases, especially when due care has not been taken to provide against exposure during convalescence." Professor Drasche ${ }^{8}$ calls attention to the strikingly frequent occurrence of relapses in the epidemic at Vienna. In the epidemic at Philadelphia " relapses were not infrequent." In 6680 cases there were 762 relapses or 11 per cent." In Germany, according to the official records, " 10 relapses varied from 10 to 40 per cent. in certain places, but as a rule were infrequent." Leyden and Guttmann ${ }^{11}$ give the results of inquiries addressed to 2849 medical men as to the frequency of relapses: 410 bad seen none, 1785 had seen them rarely, and 654 had seen them often. Parsons" states that "relapses are of frequent occurrence; they occurred in 92 of the cases at the Morningside Asylum, Edinbargh." From personal experience I would be inclined to agree with

3 Deutsche Medicinsche Wochenschrift, No. 46. pp. 865, 866. Ibid., No. 48, pp. 899 et seq

5 Zeitschrift fiin Hy giene, Band xii, 1893, p. 381.

6 Local Government Boara Additional Report. pp. 126 et seq. Influenza, p. 405 ; also pp. 358, 371 .

9 Pepper's System of Medieine, rol. i., p. 192.

10 Arbeit aus dem Kaiserlichen Gesundheitsamte, Band ix., 1894 pp. 342-344.

I1 Die Influenza-Epidemie, 1889-1890, p. 45.
12 Lozal Government Board Report, p. 68. the lower rather than with the higher of these various estimates-that. is, provided the term relapse be used in its strictest sense. A repetition of the original symptoms before convalescence was established and in the absence or complications certainly did not occur in more than ten per cent. of the cases under observation. In these cases, toor treated almost without exception with salicylate of soda, the recrudescence appeared to be sometimes due to a premature abandonment of the drug. On the whole, the conclusion may fairly be drawn from the above records that the relapse rate in influenza is not less than ten per cent.

The occurrence of multiple attacks.-Here again there is some discrepancy of opinion. Parkes, ${ }^{13}$ speaking of course of an earlier outbreak, says that "while persons seldom have an attack in the same epidemic (though even this may occur) an attack in one epidemic does not protect against a subsequent epidemic, indeed, it has been supposed rather to render the body more liable." Parsons, ${ }^{14}$ adduces a certain amount of evidence, principally in the form of opinions of medical officers of health, tending to show that one attack of influenza confers a certain though slight degree of protection. Althaus, ${ }^{15}$ a sturdy believer in the protecting powers of the disease, writing in 1891, describes the infection of two different classes of people in the first and second epidemics respectively (1889-80, and 1891), and expresses a belief that further ontbreaks are unlikely to occur on a similar scale from lack of material. The German Public Health Department ${ }^{16}$ also comes to the conclusion that influenza confers a certain power of resistance on the individual.

In the epidemic of May-June, 1891-that is, the second of the series-I treated in the casualty department at St. Thomas's Hospital 1324 patients suffering from influenza. In every case a somewhat careful investigation was made into the history of any previous attacks. Only those histories were accepted which appeared above reasonable doubt an in which the previous attack had occurred during the first epidemic. Out of these 1324 patients 89 had suffered in the first epidemic, a percentage of 6.7. Among patients who attended during the first week the percentage of multiple attacks was 134 ; among those of the last week no previous attacks had occurred. And this predominance of recurrent attacks during the early part of the period as compared with the later was apparent throughout. A percentage of 10.8 during the first fortnight fell during the last to 4.9 ; and one of 9.0 during the first month dropped in the last to 3.7 . The record was made without any previous idea as to the effect of the figures, and indeed it was not till long after the list was completed that a more careful consideration showed their significance.

The inference that individuals who have once suffered from influenza so far from enjoying any protection are more prone than others to further attacks seems irresistible; at all events they apparently are the first to succumb when exposed to fresh infection. It should be remembered that the interval between these two epidemics was at the most but four months. What is the meaning of this apparently increased susceptibility to attack? Several interpretations of it are possible. The first and most probable is that postinfluenzal debility, local or general, lasts longer than post. influenzal immunity, and so the patient is left more exposed to further attacks. Another explanation is found in the possibility that a certain proportion of the population is specially susceptible to influenza and that this excessive susceptibility is more than sufficient to counter-balance any increased power of resistance that may have been conferred by a previous infection. Some support is given to this latter suggestion by the extraordinary proclivity to the disease that certain otherwise robust individuals appear to possess; of this special proclivity many examples conld be given.

Professor Baümler, 17 in his description of the influenza epidemic in Freiburg in 1893-1894, discussing the question of acquired immunity, remarks that " most of my colleagues will answer the question-Does influenza protect?-in the negative, on the ground of their personal experience ; many were attacked this time just as they were four years ago." Having at the time of the first epidemic held a resident appointment in a large hospital I acted on this suggestion and made inquiries into the subsequent history of those who had been my colleagues on that occasion. Nine out of

13 Reynolds's System of Medicine, vol. 1., p. 35.

15 On Influenza, p. 312 . Op. cit.

17 Die In 16 Op. cit. 
twelve were available. Of these nine, two had escaped infection in the first epidemic ; of these two, one has never since contracted the disease, though repeatedly exposed to danger; the other within the last year has bad two attacks within the space of a few months. Three of the nine bave bad only one attack, two have had two, two have suffered thrice, and one has fallen victim no less than nine times. It is interesting to note the complete immunity of one, and compare it with that of his colleague who passed untouched through three epidemics and then was attacked by both the fourth and fifth. The numbers are of course too small to form a basis for serious argument, but so far as they go they certainly point to an absence of any prolonged protective influence and appear to confirm the experiences of medical victims at Freiburg.

My conclusions are (1) that the period of protection afforded by an attack of influenza is so short as to be clinically negligeable, and (2) that there is some evidence to show that there exists either a special susceptibility to the disease or an acquired predisposition to it derived from previous injections with the same virus.

Portland-place, $W$.

SUCCESSFUL CASE OF PORRO'S OPERATION IN A DWARF.

BY SMALLWOOD SAVAGE, M.A., M.B. OxoN., F.R.C.S. ENG.

A WOMAN, aged twenty-three and a half years, was sent by Dr. Baddeley, who in view of an approaching full.term pregnancy had considered there would be a good deal of difficulty in delivery. The patient's father and mother were healthy and well formed. She was the second of a family of five children all of whom, with this one exception, were of average height and merit no further mention. The patient when born was considered unusually small and "when one year old was no bigger than her newly-born sister." As an infant she was very weakly and had not sufficient strength to suck properly. She was brought up by the bottle with sago and rusks but never had any of the patent foods. She cut her teeth naturally; as to walking she did not begin until she was three years old and while at school she was much behind other girls of her own age. There was no history of fits.

On examination the patient's height was found to be only $4 \mathrm{ft} .3 \mathrm{in}$. and her weight $7 \mathrm{st} .2 \mathrm{lb}$. Her face was small but it presented an old appearance. There was no alteration in the shape of the bones of her skull or limbs, nor were there any enlarged ends of long bones. The patient had not a prominent forehead. Her teeth, however, were carious, especially in the upper jaw, for there she wore a plate. The pelvis was small; of the external measurements the intercristal was only 9 in., the interspinous only 8 in., and the external conjugate $7 \frac{1}{2}$ in. There were no signs of congenital syphilis. Mentally the patient seemed below the average. The usual signs of pregnancy were present, the uterus extending up to $1 \frac{1}{2}$ in. of the sternum. The foetal head, which was of arerage size, was felt entirely above the pelvic brim and it was impossible to make it engage it. On auscultation both souftle and foetal heart were heard. By the vagina the pubic arch was found to be very considerably contracted. The diagonal conjugate diameter was not made out The pelvis generally was a good type of the "small round pelvis." In view of the size of the child's head compared with that of the pelvis it was considered that the chances of a living child being born naturally were very remote. After due consideration of all the facts it was decided to advise delivery by Porro's operation or Cæsarean section, the former being chosen.

On Nov. 27th, 1897, the patient was operated on in my father's private hospital, Mr. J. Sandison Crabbe administering the anæsthetic and my father assisting me at the operation. The incision was made five inches long in the middle line, one third of it being above and two thirds below the umbilicus, On the uterus being exposed an attempt was made to encircle it with an elastic tourniquet; this was impracticable, so the abdominal incision was slightly enlarged above and the uterns brought out above the surface of the abdomen. The elastic tourniquet was now applied below the bead and both appendages and there temporarily fixed by forceps. Three large flat sponges were placed in the abdomen covering the remaining viscera. The placental site was felt for but could not be made out. The uterus was incised for about five inches along the anterior surface, but as this was found to be over the placenta another incision was made to the left. The membranes were ruptured and the child was quickly extracted by its neck. Before rupturing the membranes the uterus was strongly anteverted so as to allow of the uterine contents being delivered well away from the peritoneal cavity and between the mother's thighs. The clamp was next applied with a protected transfixing pin and the uterus was amputated. The abdomen was stitched up in the ordinary way, care being taken that the stump was firmly fixed in the lower angle of the wound. It might be noted that not a drop of blood or amniotic fluid entered the abdominal cavity. The child breathed well and seemed to be well formed and of average size. The patient made an uüinterrupted recovery without any untoward symptom. The clamp came away on the fifteenth day and she was discharged on Jan. 5th, 1898.

Birmingham.

\section{A. Altirror}

\author{
or
}

\section{HOSPITAL PRACTICE, BRITISH AND FOREIGN.}

Inlla autem est alia pro certo noscendi via, nisl quamplurimas morborum et dissectionum historias, tum aliorum tum proprias collectas habere, et inter se comparare.-MorgaGNI De Sed. et Caus. Morb., lib. iv. Procmium.

\section{CHARING-CROSS HOSPITAL.}

A CASE OF REMOVAL OF A PIECE OF STEEL STAYBUSK FROM THE ABDOMINAL CAVITY; RECOVERY.

(Under the care of Mr. JoHN H. MoRgan.)

ABDOMINAL operations for the removal of fortign bodies which have been swallowed are decidedly rare. Gastrotomy is the operation which is usually performed and if carried out with antiseptic precautions it is accompanied by a comparatively low mortality, for Mr. Durham ${ }^{1}$ collected a series of ten cases and of them only one died. A case recorded by Mr. Mayo Robson ${ }^{2}$ was remarkable for the very large number of foreign bodies successfally removed from the stomach of a child. In Mr. Morgan's operation, however, the foreign body had left the stomach and was found lying in the peritoneal cavity, though fortunately adhesions must have shut it off completely. A point of some interest is that the Roentgen rays gave no indication of the presence of any metallic body in the region where the piece of steel was found; a possible explanation is that the staybusk was so placed that its long axis was almost perpendicular to the sensitive plate; the result would be that a large piece of steel would give only a small image which might easily pass unnoticed.

A healthy, well-grown man, twenty-four years of age, was admitted into Charing-cross Hospital under the care of Dr. Bruce with the following story. In June, 1897, after an attack of rheumatism and owing to stress of business and home worries he had an attack of acute mania lasting three weeks, during which with an idea of suicide he swallowed the following articles: thirteen pennies, thirteen halfpennies, and ten other coins including a two-shilling-piece, a gold watch chain, a key chain, and a brass watch chain, a set of studs and a pair of sleeve-links, and half an ounce of dressmaker's pins. From the gold watch chain he removed the bar lest it should stick in his gallet. After this he suffered some pain and felt a weight in his stomach which altered in position with his movements. On Jane 25 th he found a staybusk (a piece of steel used to strengthen stays) and having picked off with his teeth the cotton which covered it be swallowed this also. He remembers hearing various articles pass into the pan of the closet, but he was unable to see what they were. In the following August he complained of some pain in his epigastric region and vomited a small

1 Erichsen's Science and Art of Surgery, tenth edition, vol i., p. 847.

2 Boston Medical and Surgical Journal, Feb. 7th, 1895. 